\title{
THE EFFECT OF BIOSCAFFOLD ALVELACTM IN PRESERVATION OF ALVEOLAR BONE AFTER EXTRACTION OF TEETH (CLINICAL AND RADIOGRAPHIC STUDY) Sager $\mathbf{M}^{1}$, Darwish $\mathrm{S}^{2}$, Melek $\mathrm{L}^{3}$
}

\begin{abstract}
Introduction: After tooth extraction, the extraction socket heals by forming a blood clot which leads to the formation of new bone within 3-4 months. Although bone deposition in the socket will continue for several months, it will not reach the crestal level of the neighboring teeth.

Objective: Is to clinically and radiographically evaluate the use of Bioscaffold Alvelac ${ }^{\mathrm{TM}}$ in preservation of dimensional measure of alveolar bone after extraction of teeth.

Materials and methods: This study was conducted on twelve patients divided in to two equal groups (study group and control group). Indicated for extraction of anterior maxillary teeth, in the study group, the bioscaffold Alvelac ${ }^{\mathrm{TM}}$ was inserted into the empty socket after extraction and was supported by 3-0 silk with figure of eight sutures. In the control group, extraction of upper anterior teeth was done without introducing any material and the wound was sutured.

Results: There was a statistically significant decrease of alveolar bone width and height in both groups at three months postoperative interval compared with the bone width and height at the immediate postoperative period.

Conclusion: Immediate tooth extraction stabilizes the bioscaffold Alvelac ${ }^{\mathrm{TM}}$ material in the socket and allows it to act as a scaffold for bone deposition. From this study, it is clear that, this material allows preservation of the dimensional measure of the alveolar bone.
\end{abstract}

Key Words: Tooth extraction, Alveolar bone, socket preservation, Scaffold, Alvelac ${ }^{\mathrm{TM}}$.

1- B.D.S.Faculty of Dentistry, Tripoli University

2- Professor of Oral \& Maxillofacial Surgery, Faculty of Dentistry, Alexandria University

3- Lecturer of Oral and Maxillofacial Surgery, Faculty of Dentistry, Alexandria University

\section{INTRODUCTION}

After loss of natural teeth, bony changes in the jaws begin to take place immediately. Since the alveolar bone no longer responds to stresses applied in this area, it begins to resorb (1).

Resorption of the alveolar ridge following extraction of hopeless teeth is recorded even when the missing teeth is immediately restored (2).

The alveolar ridge beneath the artificial teeth decreases in height and width due to lack of the stimulating effect of the teeth roots. A gap is created by time beneath the prosthesis and the ridge leading to food impaction, mucosal inflammation, and bad esthetics especially in the anterior region (3).

The remodeling process results in a ridge morphology reduced in vertical height and more palatal in relation to the original tooth position $(4,5)$.

Alveolar bone is a specialized part of the mandibular and maxillary bone that forms the primary support for the teeth. Alveolar bone is composed of bundles of bone which are built up into layers in parallel orientation to the coronal -apical direction of the tooth $(6,7)$. The bone loss is estimated to be $40 \%-60 \%$ during the first 3 years and decrease to $0.25 \%-0.5 \%$ annual loss $(8,9)$.

Immediately after tooth extraction, the alveolar socket is filled by blood clot that is replaced by granulation tissue within 1 week (10).
The bio-scaffold is made of PLGA (Polylactic-coglycolic acid) material and acts as a mechanical support to hold the blood clot at the crest level (11).

After tooth extraction, the bundle bone appears to be the first bone to be resorbed (12-14).

PLGA also has the advantage of being capable of delivering drugs, proteins and growth factors to enhance bone healing in both oral-maxillofacial and general orthopedic applications (15-18).

Brown et al (2014) (19) found in his study that sixty percent of implant-supported dental prostheses require bone grafting to enhance bone quantity and quality prior to implant placement. They have developed a metallic magnesium particle/PLGA (Mg/PLGA) composite scaffold to overcome the limitations of currently used dental bone grafting materials. These scaffolds could decrease inflammation observed with clinically used PLGA devices. These characteristics not only increase cell proliferation in vitro, but provide a safe and osteoconductive environment for bone regeneration in vivo. These findings show promising results for the use of $\mathrm{Mg} / \mathrm{PLGA}$ composite materials for a wide range of bone regeneration applications.

The aim of this study was to evaluate clinically and radiographically the use of Bioscaffold Alvelac ${ }^{\mathrm{TM}}$ in preservation of dimensional measure of alveolar bone after extraction of teeth. 


\section{MATERIALS AND METHODS}

Alvelac ${ }^{\mathrm{TM}}$ (International Pte Ltd 61 Science Park Road, \#02-05/06, The Galen, Singapore Science Park II, Singapore 117525) is a porous, osteoconductive, biocompatible and biodegradable synthetic scaffold that is synthesized from polylactic-co-glycolic acid (PLGA) and polyvinyl alcohol and produced using proprietary and patented technology.

It is a rigid structure specifically designed to prevent collapse of the buccal and lingual walls in achieving width maintenance. It is strategically placed in the extraction socket with the top of the scaffold in line with the crest of the socket in order to raise the forming blood clot to that level thus achieving height maintenance. The size of Alvelac ${ }^{\mathrm{TM}}$ does not occupy the whole socket thus allowing maximum space for blood to fill the socket. This allows for the patient's own bone to form naturally within that space by the action of Alvelac ${ }^{\mathrm{TM}}$ as scaffold (20).

\section{Selection of patients:}

Twelve patients, indicated for extraction of maxillary teeth were selected from those attending the outpatient clinic of Oral and Maxillofacial Surgery department, Faculty of Dentistry, Alexandria University.

Inclusion criteria of selection:

- Patients' age ranged between $(25-45)$ years old of both sexes.

- All patients selected were free from any relevant diseases.

- Indicated for extraction of maxillary teeth.

Exclusion criteria of selection:

- Heavy smokers.

- Bone disease (as osteoporosis).

- Uncontrolled diabetes.

Patients were divided into two equal groups; the study group, where the maxillary teeth were extracted and the bioscaffold Alvelac ${ }^{\mathrm{TM}}$ was inserted into the empty socket after extraction and was supported by 3-0 silk with a figure of eight sutures. (Fig. 1) Whereas in the control group the extraction of teeth was done without introducing any material and the wound was closed and supported by 3-0 silk with a figure of eight sutures.

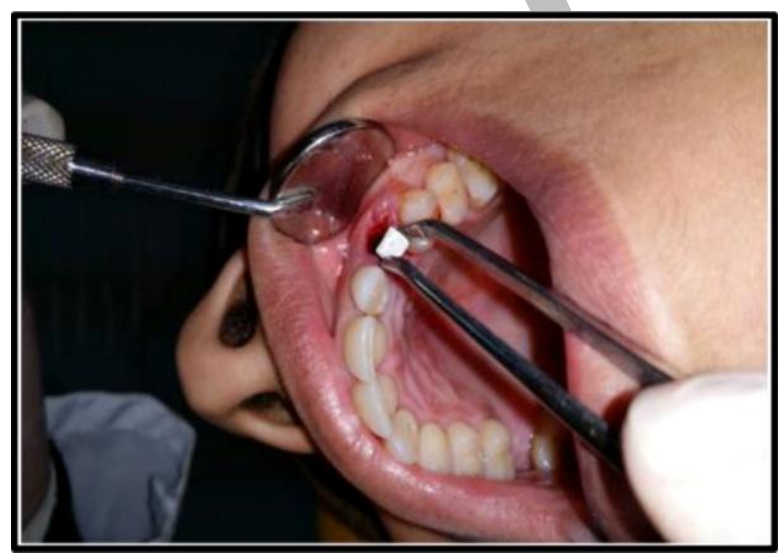

Fig (1): Showing insertion of the bioscaffold alvelac into empty socket.

A) Surgical phase: Local anesthesia (Each carpule contains $1.8 \mathrm{ml}$ mepivacaine HCL $2 \%$ produced by: Alexandria Co. for pharmaceuticals, Alexandria, Egypt). Extraction of teeth was performed using maxillary forceps.

B) Clinical follow up: All patients in the two groups were examined clinically for infection and healing. Healing was assessed by the uninterrupted (adequate \& proper) closure of the socket visually, which was done at intervals of one week, and three months after extraction.

C) Radiographic follow up: All patients in the two groups were examined radiographically immediately postoperative to serve as a baseline for measurement and after 3 months of the extraction.

The radiographic examination was done by cone beam CT (CBCT). Bone height, bone width and bone density were measured using cone beam CT (CBCT) software (On Demand 3DAPP-DBM)

\section{RESULTS:}

Twelve patients were divided equally into two groups, group I (control group) and group II (study group). Group I included 4 females (66.7\%) and 2 males $(33.3 \%)$. While group II included 5 females $(83.3 \%)$ and 1 male $(16.7 \%)$. For group I the age ranged from 25 to 40 years with mean of ( $32.17 \pm 5.71$ years). While in group II, the age ranged from 25 to 45 years with mean of $(30.83 \pm 7,22$ years $)$.

\section{Clinical Results:}

1. Infection: Infection was observed by inspection, all cases in both group I and group II showed that there were no signs of infection throughout the postoperative follow up period.

2. Healing: Normal colour of the oral mucosa and adequate closure of the extraction socket were achieved in patients of both groups. (Fig. 2)

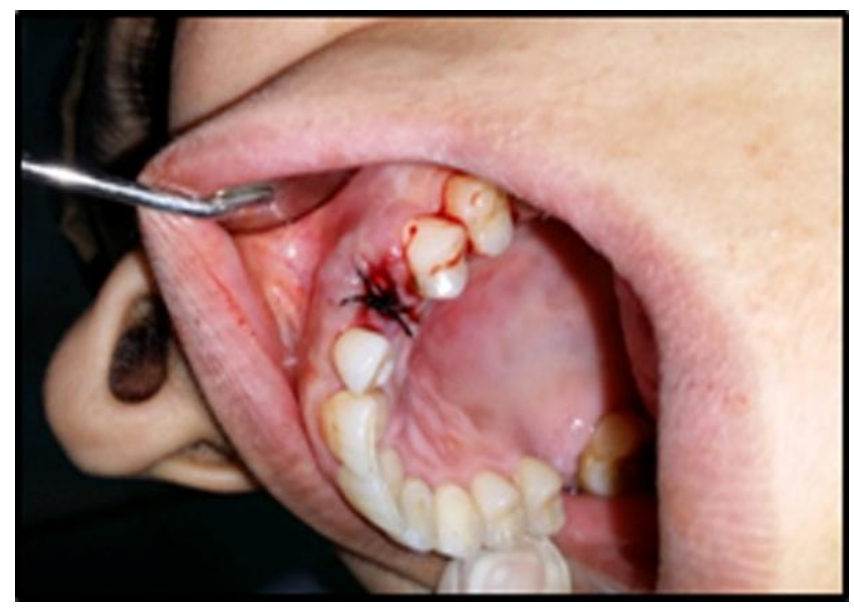


Fig (2): Showing figure of eight suture (study case).

\section{Radiographic results:}

1. Alveolar bone width (Table 1). There was a statistically significant decrease of alveolar bone width in both groups at three months postoperative compared with the bone width at the immediate postoperative period. (Fig. 3-6)

The percentage of change in alveolar bone width in group I was $18.87 \%$ while in group II it was $1.04 \%$ There was a statistically significant difference between the two groups $(\mathrm{t}=8.292, \quad \mathrm{p}=<0.001)$. 2. Vertical bone height (Table 2). There was a statistically significant decrease of alveolar bone height in both groups at three months postoperative compared with the bone height at the immediate postoperative period. (Fig. 3-6)

The percentage of change in alveolar bone height in group I was $3.68 \%$ while in group II it was $0.44 \%$. There was significant difference between the 2 groups $(\mathrm{t}=$ 5.968, $\mathrm{p}=<0.001)$.

\begin{tabular}{|c|c|c|c|c|}
\hline $\begin{array}{l}\text { Horizontal } \\
\text { (width) }\end{array}$ & $\begin{array}{c}\text { Control } \\
(\mathbf{n}=\mathbf{6})\end{array}$ & $\begin{array}{c}\text { Study } \\
(\mathbf{n}=\mathbf{6})\end{array}$ & $\mathbf{t}_{\mathbf{1}}$ & $\mathbf{p}_{\mathbf{1}}$ \\
\hline $\begin{array}{c}\text { Immediately } \\
\text { after } \\
\text { extraction } \\
\text { Min. - Max. } \\
\text { Mean } \pm \text { SD. } \\
\text { Median }\end{array}$ & $\begin{array}{c}5.70 \pm 1.39 \\
5.74\end{array}$ & $8.34 \pm 1.35$ & & \\
\hline $\begin{array}{c}\text { After 3 } \\
\text { months }\end{array}$ & 8.32 & $3.332^{*}$ & $0.008^{*}$ \\
$\begin{array}{c}\text { Min. - Max. } \\
\text { Mean } \pm \text { SD. } \\
\text { Median }\end{array}$ & $\begin{array}{c}3.13-6.68 \\
4.69 \pm 1.28\end{array}$ & $6.65-10.50$ & $4.746^{*}$ & $0.001^{*}$ \\
\hline $\begin{array}{c}\text { Change } \\
\text { after 3 } \\
\text { months }\end{array}$ & $1.01 \pm 0.27$ & $0.13 \pm 0.14$ & $7.012^{*}$ & $<0.001^{*}$ \\
\hline
\end{tabular}

Table (1): Comparison between the two groups according to horizontal bone (width) using cone beam CT.

$\mathrm{t}$ : Student t-test

$\mathrm{p} 1: \mathrm{p}$ value for student $\mathrm{t}$-test for comparing between the two groups

* significance at $\leq 0.05$

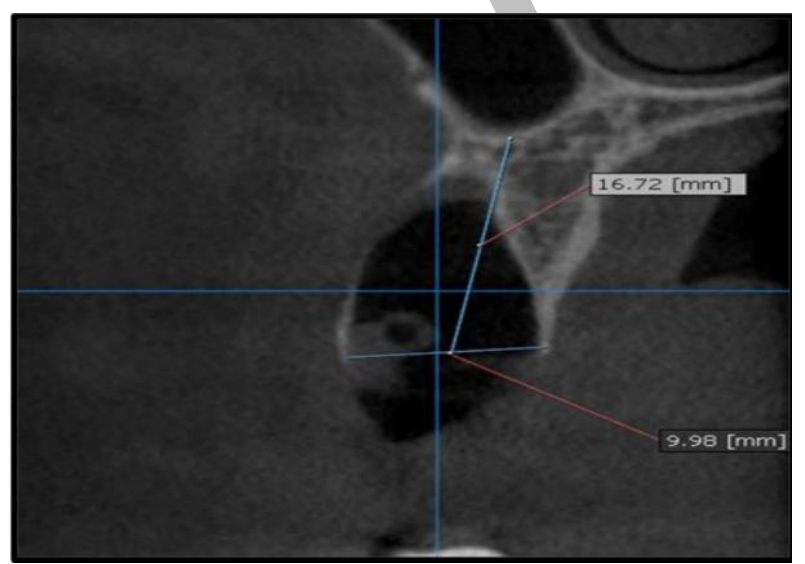

Fig (3): Showing immediate CBCT sagittal view showing alveolar bone width and alveolar bone height (control case).

3. Bone density (Table 3). There was no significant difference in bone density between group I and group II at three months postoperative.

The percentage of change in bone density for the control group was $14.87 \%$, while for study group was $22.94 \%$ with no statistically significant difference. There was a higher percentage of change in bone density in group II (study group) than in group I (control group).

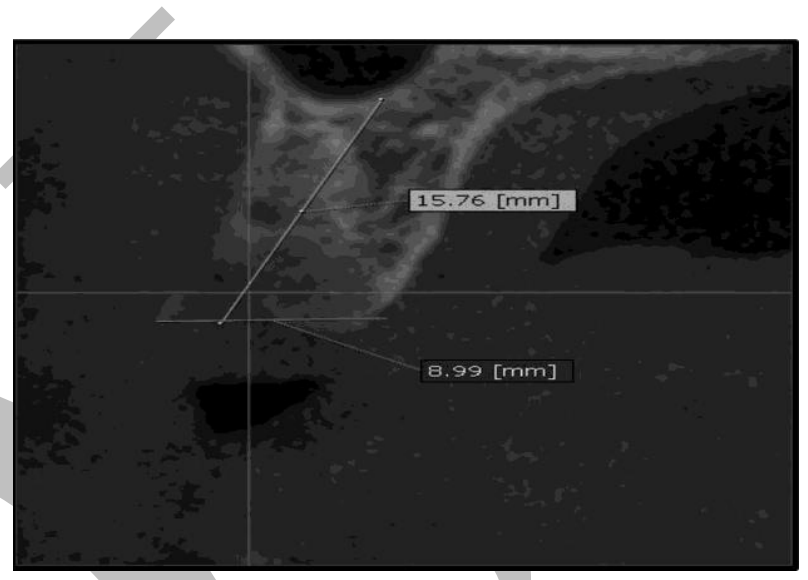

Fig (4): Showing post-operative (three months) CBCT sagittal view showing alveolar bone width and alveolar bone height (control case).

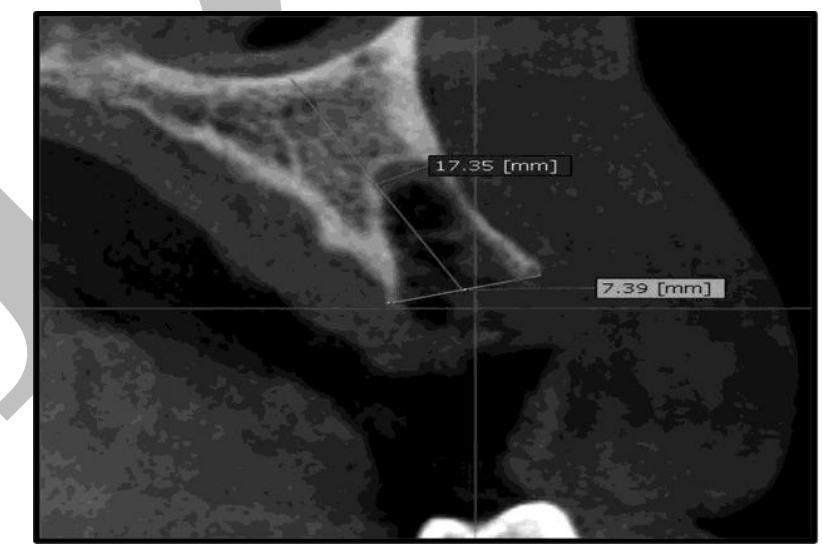

Fig (5): Showing immediate CBCT sagittal view showing alveolar bone width and alveolar bone height (study case).

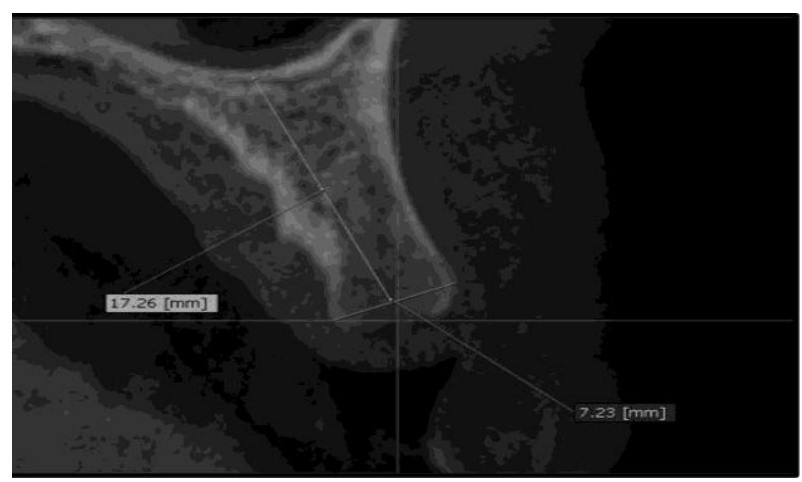


Fig (6): Showing post-operative (three months) CBCT sagittal view showing alveolar bone width and alveolar bone height (study case).

\begin{tabular}{|c|c|c|c|c|}
\hline $\begin{array}{c}\text { Vertical } \\
\text { (height) }\end{array}$ & $\begin{array}{c}\text { Control } \\
(\mathbf{n}=\mathbf{6})\end{array}$ & $\begin{array}{c}\text { Study } \\
(\mathbf{n}=\mathbf{6})\end{array}$ & $\mathbf{t}_{\mathbf{1}}$ & $\mathbf{p}_{\mathbf{1}}$ \\
\hline $\begin{array}{c}\text { Immediate } \\
\text { after } \\
\text { extraction } \\
\text { Min. - Max. } \\
\text { Mean } \pm \text { SD. } \\
\text { Median }\end{array}$ & $\begin{array}{c}15.40-22.38 \\
19.96 \pm 2.61 \\
20.38\end{array}$ & $\begin{array}{c}5.72-20.46 \\
15.78 \pm 5.49 \\
18.15\end{array}$ & 1.685 & 0.123 \\
\hline $\begin{array}{c}\text { After 3 } \\
\text { months }\end{array}$ & $14.80-21.71$ & $5.55-20.39$ & & \\
$\begin{array}{c}\text { Min. - Max. } \\
\text { Mean } \pm \text { SD. } \\
\text { Median }\end{array}$ & $19.23 \pm 2.57$ & $15.70 \pm 5.53$ & 1.416 & 0.187 \\
\hline $\begin{array}{c}\text { Change after } \\
\text { 3 months }\end{array}$ & $0.74 \pm 0.10$ & $0.08 \pm 0.06$ & $13.971^{*}$ & $<0.001^{*}$ \\
\hline
\end{tabular}

Table (2): Comparison between the two groups according to vertical bone (height) using cone beam CT. t: Student t-test $\mathrm{p} 1$ : $\mathrm{p}$ value for student $\mathrm{t}$-test for comparing between the two groups

\begin{tabular}{|c|c|c|c|c|}
\hline Bone density & $\begin{array}{c}\text { Control } \\
(\mathbf{n}=\mathbf{6})\end{array}$ & $\begin{array}{c}\text { Study } \\
(\mathbf{n}=\mathbf{6})\end{array}$ & $\mathbf{t}_{\mathbf{1}}$ & $\mathbf{p}_{\mathbf{1}}$ \\
\hline $\begin{array}{c}\text { Immediate } \\
\text { after } \\
\text { extraction }\end{array}$ & & & & \\
Min. - Max. & $210.58-513.26$ & $312.55-645.79$ & & \\
Mean \pm SD. \\
Median & $\begin{array}{c}308.58 \pm 111.32 \\
297.63\end{array}$ & $397.79 \pm 127.60$ & 1.291 & 0.226 \\
\hline $\begin{array}{c}\text { After 3 } \\
\text { months } \\
\text { Min. - Max. }\end{array}$ & $213.75-646.22$ & $325.22-821.79$ & & \\
$\begin{array}{c}\text { Mean } \pm \text { SD. } \\
\text { Median }\end{array}$ & $367.06 \pm 174.91$ & $547.78 \pm 213.54$ & 1.604 & 0.140 \\
\hline $\begin{array}{c}\text { Change after 3 } \\
\text { months }\end{array}$ & 306.69 & 515.35 & & \\
\hline
\end{tabular}

Table (3): Comparison between the two groups according to bone density using cone beam CT. $\mathrm{t}$ :Student t-test

$\mathrm{p} 1$ : $\mathrm{p}$ value for student $\mathrm{t}$-test for comparing between the two groups

\section{DISCUSSION}

The rationale for alveolar ridge preservation relies on the knowledge that the alveolar ridge resorption is an unavoidable sequelae of tooth loss (21). Its goal is to prevent the loss of $40 \%$ - $60 \%$ of ridge height and width commonly seen after extractions (8).

Preservation of socket is driven by the desire to minimize the need for future more invasive ridge augmentation procedures. Moreover, it also facilitates successful implant and conventional prosthetic treatment. Extraction site grafting often facilitates the best possible functional and aesthetic results. It is axiomatic therefore that socket preservation should be the treatment of choice to prepare the remaining alveolar ridge for conventional or fixture supported restorations $(22,23)$.

Several studies have evaluated the effect of PLGA with different grafting materials (24). Defects that were treated with $\mathrm{Mg} /$ PLGA scaffolds had an improved bone height preservation compared with empty defects at both 8 and 16 weeks post-surgery. This effect compares well with other bone-grafting materials (including polymers) that have been successfully used for socket preservation $(24,25)$.

According to Fan (26), a bio-scaffold, placed immediately after tooth extraction, helps and allows for bone to grow into it and prevents the socket from collapsing. The results of the present study are in accordance with Fan's results regarding an increase in the bone density and protection of the height and width of the alveolar bone.

A similar osteoconductive scaffold, OsteoScaf, was used by Araujo et al (27). The results obtained from CBCT measurements have clearly shown that OsteoScaf protection impaired the expected bone lost during the post extraction remodeling of the alveolar bone ridge at 120 days post extraction. This result is also in agreement with the results of the current study.

In a study by Serino et al (28), the use of a bioabsorbable synthetic sponge of polylactidepolyglycolide acid was evaluated. The results of this study indicate that alveolar bone resorption following tooth extraction may be prevented or reduced by the use of a bioabsorbable synthetic sponge of polylactidepolyglycolide acid. The quality of bone formed seemed to be optimal for dental implant insertion. The material is similar in content to Bioscaffold Alvelac ${ }^{\mathrm{TM}}$ used in the present study.

\section{CONCLUSIONS}

Within the context of this study, the following conclusions can be listed:

- Immediate tooth extraction stabilizes the bioscaffold Alvelac ${ }^{\mathrm{TM}}$ material in the socket and allows it to act as a scaffold for bone deposition.

- It is clear that this material allows preservation of the dimensional measure of alveolar bone.

- Healing seems to be more proper in the study cases.

\section{REFERENCES}

1. Browser G, Chadroff B, Carnevale R. Histologic evaluation of new attachment apparatus in human. Part П. J Periodontol 1989; 60: 675-82.

2. Kruger $\mathrm{H}$. The book of oral and maxillofacial surgery. 1st ed. Missouri: Mosby, 1984. 231.

3. Lubin CT, Lanyon LE. Osteoregulatory nature of mechanical stimuli: function as a determinant for adaptive remodelling in bone. J Orthop Res 1987; 5: $300-10$. 
4. Pagni G, Pellegrini G, Giannobile WV, Rasperini G. Postextraction alveolar ridge preservation: biological basis and treatments. Int J Dent 2012; 2012: 151030.

5. Misch CM, Misch CE. The repair of localized severe ridge defects for implant placement using mandibular bone grafts. Implant Dent 1995; 4: 261-7.

6. Truhlar RS, Orenstein IH, Morris HF, Ochi S. Distribution of bone quality in patients receiving endosseous dental implants. J Oral Maxillofac Surg 1997; 55: 38-45.

7. Lustmann J, Lewinstein I. Interpositional bone grafting technique to widen narrow maxillary ridge. Int J Oral Maxillofac Implants 1995; 10: 568-77.

8. Ashman A. Post extraction ridge preservation using synthetic alloplast. Implant Dent 2000; 9: 168-76

9. Ashman A, Rosenlicht J. Ridge preservation addressing a major problem in dentistry. Dent Today 1993; 12: 80-4.

10. Araújo MG, Lindhe J. Dimensional ridge alterations following tooth extraction. An experimental study in the dog. J Clin Periodontol 2005; 32: 212-8.

11. Chandrasekeran M, Lau S, Gunaseelan R, Prabhu V. Rapid technique to evaluate human bone quality using novel Micro CT with histology resolution. Bone 2009; 44(Suppl 2): S268.

12. Boyne PJ. Osseous repair of the postextraction alveolus in man. Oral Surg Oral Med Oral Pathol 1966; 21: 805-13.

13. Hsieh YD, Devlin H, Roberts C. Early alveolar ridge osteogenesis following tooth extraction in the rat. Arch Oral Biol 1994; 39: 425-8.

14. Devlin H, Sloan P. Early bone healing events in the human extraction socket Int J Oral Maxillofac Surg 2002; 31: 641-5.

15. Min C, Wikesjo U, Park J, Chae G, Pippig S, Bastone $\mathrm{P}$, et al. Wound healing/regeneration using recombinant human growth/differentiation factor-5 in an injectable poly-lactide-co-glycolide-acid composite carrier and a one-wall intra-bony defect model in dogs. J Clin Periodontol 2011; 38: 261-8.

16. Makadia H, Siegel S. Poly Lactic-co-Glycolic Acid (PLGA) as a biodegradable controlled drug delivery carrier. Polymers 2011; 3: 1377-97.

17. Shen H, Hu X, Yang F, Bei J, Wang S. An injectable scaffold: rhBMP-2-loaded poly(lactideco-glycolide) / hydroxyapatite composite microspheres. Acta Biomater 2010; 6: 455-65.

18. McKay W, Peckham S, Badura J. A comprehensive clinical review of recombinant human bone morphogenetic protein-2 (INFUSE Bone Graft). Int Orthop 2007; 31: 729-34.

19. Brown A, Zaky S, Ray H Jr, Sfeir C. Porous magnesium/PLGA composite scaffolds for enhanced bone regeneration following tooth extraction. Acta Biomater 2015; 11: 543-53.

20. Mikos AG, Thorsen A, Czerwonka L, Bao Y, Langer R, Winslow $\mathrm{D}$, et al. Preparation and characterization of poly (1-lactic acid) foams. Polymer 1994; 35-77.

21. Wang HL, Kiyonobu K, Neiva RF. Socket augmentation: rationale and technique. Implant dentistry 2004; 13: 286-96.

22. Fickl S, Zuhr O, Wachtel H, Bolz W, Huerzeler M. Hard tissue alterations after socket preservation: an experimental study in the beagle dog. Clin Oral Implant Res 2008; 19: 1111-8.

23. Sethi A, KausT. Maxillary ridge expansion with simultaneous implant placement: a 5-year results of an ongoing clinical study. Int $\mathbf{J}$ Oral Maxillofac Implants 2000; 15: 491-9.

24. Dobrovolskaia MA, Aggarwal P, Hall JB, McNeil SE. Preclinical studies to understand nanoparticle interaction with the immune system and its potential effects on nanoparticle biodistribution. Molecular pharmaceutics 2008; 5: 487-95.

25. Serino G, Rao W, Iezzi G, Piattelli A. Polylactide and polyglycolide sponge used in human extraction sockets: bone formation following 3 months after its application. Clin Oral Implant Res 2008;19(1):1631.

26. Fan V. Sacaffold to aid tooth implants. NUH 2008; 26: $1-2$.

27. Araujo AC, Mendes VC, Junior OF, Carvalho PS, Guan L, Davies JE. Investigation of a Novel PLGA/CaP Scaffold in the Healing of Tooth Extraction Sockets to Alveolar Bone Preservation in Humans. Clin Implant Dent Relat Res 2015; 5: 1-12.

28. Serino G, Biancu S, Iezzi G, Piattelli A. Ridge preservation following tooth extraction using a polylactide and polyglycolide sponge as space filler: a clinical and histological study in humans. Clin Oral Implant Res 2003; 14: 651-8. 